\title{
Infecção pelo vírus da hepatite A em área indígena da Amazônia oriental brasileira
}

\author{
Hepatitis A virus infection in Amerindian area in \\ the east Brazilian Amazon
}

\author{
Heloisa Marceliano Nunes ${ }^{1}$, Manoel do Carmo Pereira Soares ${ }^{1}$ \\ e Helena Maria Ribeiro Silva ${ }^{2}$
}

\begin{abstract}
RESUM0
A hepatite viral A representa importante problema de saúde pública em todo o mundo, estando relacionada às condições sócioeconômicas e de higiene da população. Na Amazônia brasileira, estudos soroepidemiológicos em populações indígenas tem demonstrado alta endemicidade relacionada à infecção. Objetivando avaliar a prevalência da infecção pelo vírus da hepatite A em aldeia xicrin, no município de Altamira-Pará-Brasil, cuja investigação foi desencadeada por óbito de criança in dígena, que evoluiu clinicamente em nove dias, com quadro ictero-hemorrágico, sem realização de exame sorológico, foram analisadas 352 amostras de sangue através de testes sorológicos dos marcadores virais das hepatites A, B, C e D, por técnica imunoenzimática, que indicaram uma prevalência de $98 \%$ de anticorpos contra a hepatite A e destes, 30,5\% com infecção recente, caracterizando em base laboratorial, o surto de infecção pelo vírus da hepatite A e levantando a possibilidade de estar associado com o óbito ocorrido na aldeia.
\end{abstract}

Palavras-chaves: Hepatite A. Epidemiologia. Indígenas. Amazônia.

\begin{abstract}
The hepatitis A virus infection represents an important problem of public health all over the world, being related to the socioeconomic and hygienic conditions of the population. In Brazilian Amazon, seroepidemiological studies in amerindians populations have been demonstrating high endemicity related to the infection. With the objective of evaluate the prevalence of the hepatitis virus A infection in xicrin village, in the municipality district of Altamira-Pará-Brazil, whose investigation was unchained by indigenous child's obit, that clinical developed in nine days with a picture icterus-hemorrhagic, without confirmation by serologic exams, 352 samples of blood were analyzed by serologic tests of the markers of the hepatitis A, B, C and D virus, for immunoenzymatic technic, that indicated a prevalence of $98 \%$ of antibodies against the hepatitis A virus, which $30,5 \%$ with recent infection, characterizing in laboratorial basis, the outbreak of infection for the virus of the hepatitis A and raising the possibility to be associated with the obit happened in the village.
\end{abstract}

Key-words: Hepatitis A. Epidemiology. Amerindians. Amazon

A hepatite viral A representa grave problema de saúde pública em todo o mundo, conhecida também como hepatite infecciosa, epidêmica, MS-1 ou hepatite de incubação curta, tem como agente etiológico 0 vírus da hepatite $\mathrm{A}(\mathrm{HAV})^{5}$, da família Picornaviridae, gênero Hepatovirus ${ }^{10}$, com diâmetro de $27-28 \mathrm{~nm}$, forma esférica, não envelopado, genoma constituído de RNA de fita simples com cerca de 7.474 nucleotídeos, transmissão através da via fecal-oral por veiculação hídrica e alimentos contaminados, pode ser encontrado nas fezes, três semanas antes a duas semanas depois do início dos sintomas, possui curto tempo de viremia e baixa concentração viral no sangue, à exceção das formas prolongadas, onde pode ser detectado nas fezes por alguns meses após 0 início do quadro clínico ${ }^{19}$, infectante mesmo após sua permanência por cerca de quatro semanas à temperatura ambiente, pode ser inativado pela fervura de cinco minutos, por solução de formol $\leq$ a 1: 4.000 e pelo hipoclorito de sódio 1mg/L por trinta minutos ${ }^{1316}$.

1. Instituto Evandro Chagas da Secretaria de Vigilância em Saúde do Ministério da Saúde, Belém PA, 2. Distrito Sanitário Especial Indígena de Altamira da Fundação Nacional de Saúde do Ministério da Saúde.

Endereço para correspondência: Dra. Heloisa Marceliano Nunes. Travessa Rui Barbosa 791, Reduto, 66053-260 Belém, PA.

e-mail: heloisanunes@iec.pa.gov.br 
0 diagnóstico etiológico é feito através da pesquisa dos marcadores sorológicos anti-HAV IgM, detectado desde 0 início das manifestações clínicas até 4-6 meses após estas manifestações indicando infecção atual ou recente pelo $\mathrm{HAV}$; pelo anti-HAV IgG, que surge uma semana após o início dos sintomas e indica infecção pregressa ou fase de convalescença, confirmando exposição passada e imunidade contra 0 HAV por infecção, vacinação adequada e transitoriamente sintomática ou assintomática após 0 uso de imunoglobulina ou transfusão sanguínea; e pelo anti-HAV total, que detecta ambos os anticorpos, necessitando de testagem das frações.

A doença não evolui para a cronicidade, nem para estado de portador, podendo evoluir para formas graves ou fulminantes ${ }^{811}$, a mortalidade ocorre em menos de 1:1.000 casos, pequeno percentual de infectados pode evoluir para recaída, num curso bifásico ou prolongado, com anti-HAV IgM persistindo em títulos baixos por até 12-14 meses.

Édoença de distribuição universal, há mais de dois mil anos Hipócrates já descrevia casos de icterícia epidêmica, provavelmente devido à hepatite A, não havendo dados exatos sobre a sua incidência, devido serem a maioria das infecções assintomática ou de leve sintomatologia. 0 contato entre familiares na mesma habitação, o confinamento, a falta de hábitos de higiene pessoal e coletivo, a manipulação de alimentos por pessoas infectadas, propiciam a disseminação do vírus.

Medidas de saneamento básico como o controle da qualidade da água e destino adequado dos dejetos humanos; educação em saúde com informaçoes sobre higiene pessoal e coletiva, sobre a doença e forma de transmissão podem colaborar para a redução da sua incidência. 0 uso de gamaglobulina humana ${ }^{7}$ até à bem pouco tempo, era a única medida de controle especíicico contra a hepatite A, indicada para contatos de infecção aguda ou para acidentados com material biológico contaminado com 0 vírus. As vacinas contra a hepatite Adesenvolvidas recentemente, utilizando vírus inativados por formaldeído, com ou sem fenoxietanol como preservativo, no Brasil, estão disponíveis apenas nos Centros de Referência de Imunobiológicos Especiais (CRIE) e indicadas somente para hepatopatas crônicos suscetíveis para a hepatite $\mathrm{A}^{6}$.

Facilmente propagável, a infecção pelo HAV mundialmente, apresenta regiões geográficas de alta, intermediária e baixa endemicidade ${ }^{18}$, onde alta endemicidade, caracteriza-se pela ampla disseminação do vírus devido condições sanitárias e de higiene desfavoráveis, típica dos países em desenvolvimento como partes da África, Ásia, Américas Central e do Sul, nestas, a infecção ocorre precocemente em crianças menores de cinco anos de idade, geralmente assintomática ou com leve sintomatologia e com rara ocorrência de epidemias ${ }^{15}{ }^{18}$; nas áreas de endemicidade intermediária, encontramos condições sanitárias e de higiene variável, mas com alta circulação do HAV, apresentando surtos epidêmicos que atingem principalmente adolescentes e adultos jovens, como ocorre nos países do leste europeu, das repúblicas da antiga União Soviética e partes das Américas e da Ásia12; nas áreas de baixa endemicidade com boas condições sanitárias e de higiene, como os países industrializados, são encontradas baixas taxas da infecção na população em geral, sendo que os casos acometem adultos em idade mais avançada com surtos localizados, relacionados a grupos de risco ( turistas, presidiários, doentes mentais em asilos, militares, usuários de drogas injetáveis, homossexuais) ${ }^{17}$ ou por contaminação de fontes de abastecimento de água ${ }^{9}$, pois a água constitui um importante meio de propagação do $\mathrm{HAV}$, principalmente onde não existem medidas adequadas de saneamento básico.

Estudos de soroprevalência para hepatite A realizados na Amazônia brasileira, apontam a região Norte como área de alta endemicidade, com soroprevalência de $92,8 \%$, maior que a média nacional que é de $64,7 \%{ }^{4}$. Estudo realizado em $1986^{12}$ nos municípios de Boca do Acre/AM e Sena Madureira/AC demonstrou que as hepatites virais tem grande importância na morbidade e mortalidade na Bacia Amazônica, com taxa de mortalidade por hepatite cinco a dez vezes maior que a média do resto do continente americano. Em Boca do Acre, 0 estudo demonstrou que a maioria das infecções foi adquirida precocemente antes dos 14 anos de idade na área urbana e mais tardiamente depois dos 30 anos na área rural.

Estudo de incidência realizado em Marabá, $\mathrm{PA}^{3}$ revelou que dos 51 casos consecutivos levantados de síndrome ictérica, $74,6 \%$ foram considerados hepatites, dos quais 13,7\% detectados como hepatite A. Ainda em Marabá/PA, estudo de prevalência ${ }^{1}$ demonstrou alta endemicidade do anti-HAV, onde dois terços das infecções ocorreram até os três anos de idade, com 100\% de imunidade aos cinco anos.

No Estado do Pará ${ }^{14}$, o coeficiente de morbidade /100.000 habitantes para hepatite A, variou em 1997 de 7,6\%, em 1998 de 9,6\% e em 1999 de 6,6\%, caracterizando acentuada subnotificação dos casos no estado, quando comparado no mesmo período com as hepatites B (60,4\%), C (55,2\%) e não-A não-B ( $82,3 \%)$.

Entre a população indígena da Amazônia brasileira, estudos soroepidemiológicos ${ }^{1}$ demonstram alta endemicidade relacionada as hepatites virais, porém com bastante carência de informações sobre a maioria das comunidades, pois além dos aspectos clínico-laboratóriais devem ser levados em conta aspectos socioculturais, antropológicos, geográficos, epidemiológicos e de representação social do processo saúde-doença de cada povo, que irão interferir na manutenção e propagação de doenças, como a hepatite A.

Objetivamos com este estudo, avaliar a prevalência da infecção pelo vírus da hepatite A em aldeia xicrin, no município de Altamira, Pará, Brasil, desencadeada por investigação do óbito de criança indígena devido quadro séptico, broncopneumonia e hepatite, sem a realização de exame sorológico.

\section{MATERIAL E MÉTODOS}

Atendendo a solicitação do Distrito Sanitário Especial Indígena (DSEI) Altamira, em novembro de 2002, equipe formada por técnicos do Instituto Evandro Chagas (IEC), Belém, Pará, trabalhou junto à área indígena xicrin, em Altamira, Estado do Pará, investigando a ocorrência de óbito de indígena, com seis anos de idade que evoluiu clinicamente em nove dias, com quadro ictero-hemorrágico. 
0 trabalho desenvolvido teve como etapas: reunião com a equipe do DSEI/Altamira para organizar a viagem para a aldeia, levantar informações sobre 0 caso e sobre 0 censo populacional da comunidade; reunião no hospital municipal de Altamira com 0 médico que fez 0 atendimento, conseguindo cópias do prontuário, do registro de óbito do indígena e da ficha de notificação do caso, infelizmente não foi possível resgatar amostras do paciente para exames sorológicos, pois foram descartadas após utilização pelo laboratório do hospital; deslocamento aéreo até a aldeia e reunião com 0 cacique e guerreiros explicando 0 objetivo da viagem $\mathrm{e}$ pedindo autorização para desenvolver as atividades de pesquisa; preenchimento de ficha individual do inquérito que incluía dados de identificação, clínicos e epidemiológicos; coleta de 10ml de sangue em média dos adultos e $5 \mathrm{ml}$ das crianças para exames sorológicos das hepatites virais da população presente na aldeia, com exceção dos menores de um ano, que a pedido das mães foram excluídos da coleta e dos indígenas que não aceitaram participar da pesquisa; centrifugação, acondicionamento e refrigeração das amostras em gelo comum até seu transporte ao IEC; investigação do caso índice, dos contatos e de casos suspeitos; mapeamento da aldeia; reunião final com toda comunidade indígena para agradecer a sua colaboração, informar sobre as atividades realizadas durante a permanência da equipe na aldeia, medidas de prevenção, exames que serão realizados e envio dos resultados através do DSEI/Altamira.

Na Seção de Hepatologia do IEC, foram realizados testes de marcadores sorológicos do vírus da hepatite A (anti-HAV
IgM, anti-HAV total), do vírus da hepatite B (HBsAg, anti$\mathrm{HBc}$ total, anti-HBs), do vírus da hepatite $\mathrm{C}$ (anti-HCV) e do vírus da hepatite D (anti-HDV total nas amostras reagentes ao vírus da hepatite B) , por técnica imunoenzimática.

\section{RESULTAD0S}

Aaldeia xicrin, localizada no município de Altamira ( Figura 1), fica a $228 \mathrm{~km}$ da sede do município, sendo acessível por via aérea ( 45 minutos de vôo) e por via fluvial (dois dias de viagem em voadeira), situa-se a margem esquerda do rio Bakajá e tem uma população de 410 índios. A aldeia, de formato circular ( Figura 2), conta com 35 habitações de barro e madeira, teto de palha, piso de chão batido, tendo a cozinha como anexo. A base alimentar da população é constituída de farinha e bejú de produção própria, raízes e frutas. Alimentamse também de galinha, peixe, carne de caça e esporadicamente utilizam produtos industrializados.

0 sistema de abastecimento de água utiliza bomba movida por motor a óleo diesel e tem capacidade de armazenamento de 3.000 litros, funcionando de forma irregular, dois poços artesianos bombeados manualmente e 0 rio Bakajá são as outras fontes de abastecimento de água. Todas as casas da

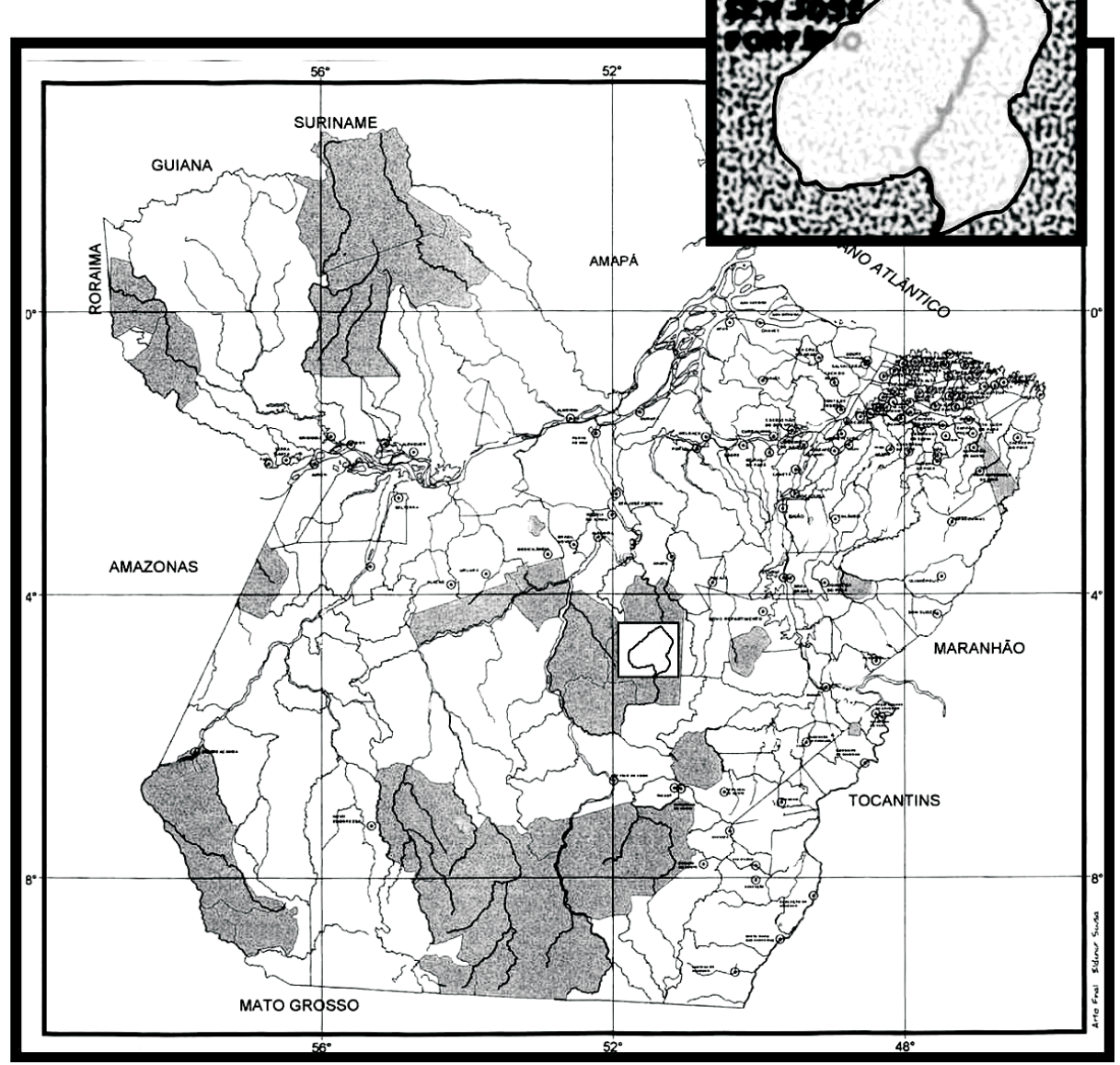

Adaptado de Laboratório de Sensoriamento Remoto - LSR/Sectam - Secretaria Executiva de Ciência, Tecnologia e Meio Ambiente do Estado do Pará.

Figura 1 - Localização geográfica da área indígena xicrin. 


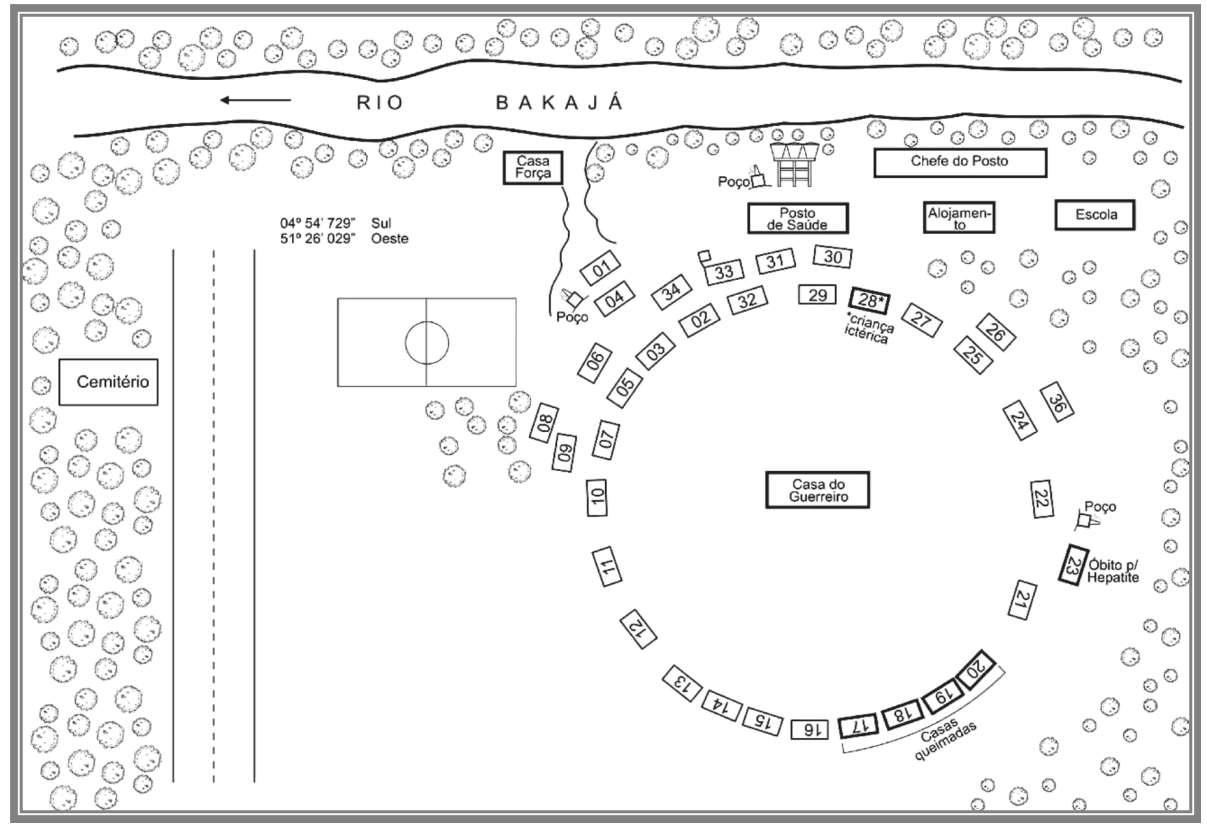

Figura 2 - Esquema da aldeia xicrin.

aldeia tem privadas de fossa seca, utilizadas pela população adulta, 0 mesmo não se aplicando às crianças que comumente defecam a céu aberto. 0 lixo é varrido e geralmente queimado pelas mulheres. As casas são supridas com energia elétrica fornecida por motor de luz, movido a óleo diesel, também de forma irregular. Observamos grande quantidade de cães domésticos coabitando com os índios e material fecal de origem canina espalhado por toda a aldeia.

0 estudo incluiu 352 indígenas, sendo $181(51,4 \%)$ do sexo masculino, com idade média de 37,5 anos (1-74), os testes para detecção de anticorpos contra a hepatite $\mathrm{A}$, indicaram que na aldeia xicrin, a prevalência da infecção foi de $98 \%$ e destes 30,5\% com infecção recente (anti-HAV IgM positivo), dos casos recentes 89\% estavam na faixa até dez anos de idade, sem predomínio quanto ao sexo ( Tabela 1). Com relação aos outros marcadores virais, houve positividade de três amostras para $0 \mathrm{HBsAg}(0,9 \%)$, de 16 amostras para 0 anti-HBc (19\%) e nenhuma amostra foi positiva para anti-HCV ou anti-HDV.

\section{DISCUSSÃO}

Caracterizamos, em base laboratorial, o surto de infecção pelo vírus da hepatite A na aldeia xicrin, levantando a possibilidade de estar associado com o óbito ocorrido na aldeia. 0 contato com outras populações não-índias, 0 contato dos infectados na mesma habitação, a manipulação de alimentos, os hábitos de higiene próprios de sua cultura, as dificuldades com relação ao abastecimento de água e destino adequado de dejetos humanos propiciaram a disseminação do vírus. 0 hábito de visitar e receber visitas de outras comunidades indígenas pode levar inclusive à disseminação do vírus entre os susceptíveis de outras aldeias. Medidas de saneamento básico e de educação em saúde podem colaborar para a redução da incidência da hepatite A na população indígena.

A vacina contra a hepatite A, no Brasil, disponível apenas nos Centros de Referência de Imunobiológicos Especiais (CRIE), e indicada somente para hepatopatas crônicos suscetíveis à hepatite A, em face das características sócioculturais, antropológicas, geográficas, epidemiológicas e de representação social do processo saúde-doença de cada

Tabela 1 - Prevalência de anticorpos contra 0 vírus da hepatite A em indígenas de aldeia xicrin, por faixa etária e sexo, Altamira-Pará-Brasil. Novembro/2002.

\begin{tabular}{|c|c|c|c|c|c|}
\hline \multirow[b]{2}{*}{ Faixa etária (anos) } & \multirow{2}{*}{$\begin{array}{c}\text { População } \\
\text { examinada } \\
n^{0} \underline{ }\end{array}$} & \multicolumn{2}{|c|}{$\begin{array}{l}\text { Anti-HAV total } \\
\text { positivo }\end{array}$} & \multicolumn{2}{|c|}{$\begin{array}{l}\text { Anti-HAV IgM } \\
\text { positivo }\end{array}$} \\
\hline & & $\mathrm{n}^{0}$ & $\%$ & $\mathrm{n}^{0}$ & $\%$ \\
\hline $1-4$ & 79 & 76 & 96,2 & 50 & 65,8 \\
\hline $5-9$ & 76 & 76 & 100,0 & 43 & 56,6 \\
\hline $10-14$ & 50 & 49 & 98,0 & 5 & 10,2 \\
\hline $15-19$ & 31 & 30 & 97,8 & 3 & 10,0 \\
\hline $20-24$ & 27 & 27 & 100,0 & 1 & 3,7 \\
\hline $25-29$ & 24 & 24 & 100,0 & 0 & 0 \\
\hline $30-34$ & 16 & 15 & 94,0 & 1 & 6,7 \\
\hline $35-39$ & 8 & 8 & 100,0 & 1 & 12,5 \\
\hline $40-44$ & 9 & 9 & 100,0 & 0 & 0 \\
\hline $45-49$ & 10 & 10 & 100,0 & 0 & 0 \\
\hline $50-54$ & 4 & 4 & 100,0 & 0 & 0 \\
\hline $55-59$ & 6 & 6 & 100,0 & 1 & 16,7 \\
\hline $60-64$ & 7 & 7 & 100,0 & 0 & 0 \\
\hline $65-69$ & 3 & 3 & 100,0 & 0 & 0 \\
\hline $70-74$ & 2 & 2 & 100,0 & 0 & 0 \\
\hline \multicolumn{6}{|l|}{ Sexo } \\
\hline masculino & 181 & 178 & 98,3 & 52 & 29,2 \\
\hline feminino & 171 & 167 & 97,7 & 53 & 31,8 \\
\hline Total & 352 & 345 & 98,0 & 105 & 30,5 \\
\hline
\end{tabular}


povo indígena, interferindo na manutenção e propagação de doenças, merece ter sua utilização discutida, como o recurso mais efetivo para 0 controle da hepatite nessas comunidades.

\section{AGRADECIMENTOS}

À equipe do DSEI-Altamira que nos auxiliou no desenvolvimento da pesquisa, às lideranças indígenas xicrin, que consentiram que a mesma fosse desenvolvida em sua aldeia e aos técnicos da seção de Hepatologia do IEC, pela ajuda imprescindível na coleta e execução dos exames sorológicos.

\section{REFERÊNCIAS BIBLIOGRÁFICAS}

1. Bensabath G, Hadler SC, Soares MCP, Fields H, Maynard JE Caracteristicas serologicas y epidemiologicas de la hepatitis virica aguda em la cuenca Amazonica del Brasil. Boletim de la Oficina Sanitaria Panamericana 103: 351-361, 1987.

2. Bensabath G, Soares MCP. A Febre Negra de Lábrea e infecções pelo vírus Delta. Instituto Evandro Chagas: 50 anos de contribuição às ciências biológicas e à medicina tropical., Fundação Serviços de Saúde Belém 2: 536, 1986.

3. Bensabath G, Soares MCP, Maia MMS. Hepatite por vírus. Instituto Evandro Chagas: 50 anos de contribuição às ciências biológicas e à medicina tropical. Fundação Serviços de Saúde Pública, Belém 1: 483-529, 1986.

4. Clemens SAC, Fonseca JC, Azevedo T, Cavalcante A, Silveira TR, Castilho MC, Clemens R. Soroprevalência para hepatite A e hepatite B em quatro centros no Brasil. Revista da Sociedade Brasileira de Medicina Tropical 33: 01-10, 2000.

5. Feinstone SM, Kapikian AZ, Purcel RH. Hepatitis A: detection immune electron microscopy of a viruslike antigen associated with acute illness. Science 182:1026-1028, 1973.

6. Fundação Nacional de Saúde. Imunizações: Imunobiológicos Especiais e suas indicações. [online] acesso em 04 dez 2002. Disponível em <http:/ /www.funasa.gov.br/imu/indicacoes.htm>, 2001.
7. Katkov WN, Dienstag JL. Hepatitis vaccines. Gastroenterology Clinics of North America 24: 147-159, 1995.

8. Masada CT, Shaw BWJ, Zetterman RK, Kaufman SS, Markin RS. Fulminant hepatic failure with massive necrosis as a result Hepatitis A infection. Journal of Clinical Gastroenterology 17: 158-162, 1993.

9. Melnick JL. History and epidemiology of Hepatitis A. The Journal of Infectious Diseases 171: S2-8, 1995.

10. Minor P. Picornaviridae. In: Francki RIB, Fanquel CM, Knudson DL, Brown F (eds) Classification and nomeclature of viruses Archives of Virology. Wien, Springer-Verlag, Supl 2, p. 326, 1991.

11. Moreira-Silva SF, Frauches DO, Almeida AL, Mendonça HFMS, Pereira FEL. Acute liver failure in children: observations in Vitória, Espírito Santo State, Brazil. Revista da Sociedade Brasileira de Medicina Tropical 35: 483-486, 2002.

12. Santos MV, Lopes MH. Vacina inativada contra a Hepatite A: Revisão da literatura e considerações sobre seu uso. Revista da Sociedade Brasileira de Medicina Tropical 30: 145-157, 1997.

13. Scholz E, Heinricy U, Flehmig B. Acid stability of hepatitis virus. Journal of General Virology 70:2481-2485,1989.

14. Secretaria Especial de Estado de Proteção Especial. Relatório das atividades do Núcleo Estadual de Epidemiologia. da Secretaria Executiva de Saúde Pública do Pará, Belém, 2001.

15. Shapiro CN, Margolis HS. Worldwide epidemiology of hepatitis A virus infection. Journal of Hepatology 18: S11-S14, 1993.

16. Siegl G, Frösner GG, Gauss-Muller V, Trastschin JD, Deinhardt F. The physicochemical properties of infections hepatitis A virions. Journal of General Virology 57: 331-341,1981.

17. Van Damme P, Mathei C, Thoelen S, Meheus A, Safary A, André FE. Single dose inactivated Hepatitis A vaccine: rationale and clinical assessment of the safety and immunogenicity. Journal of Medical Virology 44: 446-451, 1994.

18. World Health Organization. Public health control of hepatitis A: memorandum from a WHO meeting. Bulletin of the World Health Organization 73: 15-20, 1995.

19. Yotsuyanagi H, Koike K, Yasuda K, Moriya K, Shintani Y, Fujie H, Kurokawa K. Prolonged fecal excretion of hepatitis A virus in adult patients with hepatitis $\mathrm{A}$ as determined by polymerase chain reaction. Hepatology 24: 10-13, 1996. 